\title{
Effect of pedicle-screw rod fixation on oblique lumbar interbody fusion in patients with osteoporosis: a retrospective cohort study
}

Kaiwen Cai ${ }^{1,2+}$, Kefeng Luo ${ }^{1,2+}$, Jinjin Zhu ${ }^{3}$, Kai Zhang ${ }^{1,2}$, Shengkai Yu ${ }^{4}, Y i$ Y $e^{1,2}$ and Guoqiang Jiang ${ }^{1,2^{*}}$

\begin{abstract}
Study design: A retrospective cohort study.

Objective: To investigate the radiological and clinical outcomes of patients with or without pedicle-screw rod fixation (PSRF) in OLIF surgery.

Methods: Between June 2017 and December 2019, 66 consecutive patients who underwent OLIF surgery at two centers were divided into stand-alone and combined groups according to whether or not PSRF was used. Imaging and clinical data were collected preoperatively, postoperatively, 3 and 6 months postoperatively, and at the last follow-up. Related coefficient and multiple linear regression analysis was used to detect the influencing factors of cage subsidence (CS).

Results: There was a lower baseline BMD in the combined group $(p=0.005)$. The combined group showed superior VAS score at 3 months postoperatively, although there was no difference in long-term VAS and ODI scores between the two groups. The foraminal height $(\mathrm{FH})$ of the two groups was comparable at preoperatively, postoperatively, and 3 months postoperatively, but the combined group showed better maintenance of FH at 6 months postoperatively $(p=0.049)$ and last follow-up $(p=0.019)$. The total CS (tCS) of the combined group was lower than that of the stand-alone group during the whole follow-up period (all $p \leq 0.001$ ). Multiple linear regression suggested that lower BMD was the risk factor for main CS, and PSRF could significantly reduce the BMD threshold for severe CS (-4.77 vs -1.38$)$.
\end{abstract}

Conclusions: OLIF combined with PSRF can effectively avoid foraminal height loss and prevent severe CS, which may be more suitable for patients with osteoporosis or osteopenia and improve clinical outcomes.

\footnotetext{
* Correspondence: jiangguoqiang@nbu.edu.cn

${ }^{\dagger}$ Kaiwen Cai and Kefeng Luo are co-first authors.

'Department of Orthopaedic, The Affiliated Hospital of Medical School of

Ningbo University, No. 247, Renmin Road, Jiangbei District, Ningbo, Zhejiang,

People's Republic of China

${ }^{2}$ Institute of Orthopaedics, Ningbo University, Ningbo, People's Republic of

China

Full list of author information is available at the end of the article
}

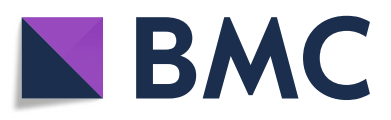

(- The Author(s). 2021 Open Access This article is licensed under a Creative Commons Attribution 4.0 International License, which permits use, sharing, adaptation, distribution and reproduction in any medium or format, as long as you give appropriate credit to the original author(s) and the source, provide a link to the Creative Commons licence, and indicate if changes were made. The images or other third party material in this article are included in the article's Creative Commons licence, unless indicated otherwise in a credit line to the material. If material is not included in the article's Creative Commons licence and your intended use is not permitted by statutory regulation or exceeds the permitted use, you will need to obtain permission directly from the copyright holder. To view a copy of this licence, visit http://creativecommons.org/licenses/by/4.0/. The Creative Commons Public Domain Dedication waiver (http://creativecommons.org/publicdomain/zero/1.0/) applies to the data made available in this article, unless otherwise stated in a credit line to the data. 


\section{Background}

Oblique lumbar interbody fusion (OLIF) has become a widely used indirect decompression and interbody fusion technique in the last decade. The rudiment of the OLIF operation method was described by Dr. Mayer [1] in 1997, who established a working channel between the left psoas major muscle and the abdominal vascular sheath and completed intervertebral fusion via this channel. Due to its minimally invasive advantages and allowing the implantation of a larger cage $[2,3]$, it has become one of the main surgical methods for the treatment of degenerative lumbar instability.

Because it is believed that the large size of the cage can provide adequate stability, many scholars have used the stand-alone OLIF method to stabilize the intervertebral space and achieved good clinical results [4-6]. However, the stability of stand-alone OLIF has attracted attention and been researched recently. Fang $\mathrm{G}$ et al. reported that the segment stability of the stand-alone OLIF was worse than that of the OLIF combined with bilateral pedicle screw fixation method; endplate stress was more close to the yield stress of the lamellar bone that means the patients who underwent stand-alone OLIF might face a greater risk of cage subsidence (CS) [7]. Remarkable CS is considered to be significantly related to worse clinical outcomes [8]. What's worse, existing studies have shown a non-negligible incidence of CS during OLIF [8-11].

Based on experience, risk factors for CS include endplate injury, osteoporosis, grade II spondylolisthesis or above, isthmic spondylolisthesis, and multilevel fusion [3]. To avoid this risk, additional fixation was introduced for the OLIF procedure, resulting in combined OLIF. Among all additional implantation, pedicle-screw rod fixation (PSRF) is the most commonly used, not only it disperses the stress transfer and protects the endplate but it also increases the operation time, medical cost, intraoperative bleeding amount, and invasion of paraspinal tissue. At present, the evidence on the risks and benefits of stand-alone/PSRF is mixed, and it is still not clear when additional PSRF is necessary in OLIF surgery.

The purpose of this study was to clarify the effect of PSRF on preventing CS in OLIF surgery and to further clarify the indications of its use.

\section{Methods and materials}

This study was approved by the clinical ethics committee of The Affiliated Hospital of Medical School of Ningbo University (KY20200906). Due to the retrospective nature of this study, the written informed consent of patients was waived.

\section{Patient selection}

From June 2017 to December 2019, 94 consecutive patients underwent OLIF with or without PSRF surgery in two centers; the medical records of them were reviewed. The inclusion criteria were as follows: (1) Patients who underwent OLIF surgery with or without PSRF, (2) conservative treatment was ineffective for 3 months, and (3) pain symptoms are mainly low back pain, radiculotic symptoms are not or mild. The exclusion criteria were as follows: (1) Patients combined with any direct decompression, (2) patients with incomplete radiological data, (3) patients who were lost or had incomplete follow-up records, (4) patients received a change in the implantation method for revision surgery, and (5) multilevel surgery.

As a result, sixty-six patients were enrolled. The average follow-up period was $22.6 \pm 6.6$ months (range 1334 months). Among the 66 patients included, 41 patients who received stand-alone OLIF were set as the standalone group, and 25 patients who received OLIF combined with bilateral PSRF were set as the combined group. Among the 28 excluded patients, 17 cases were lost, 8 cases had incomplete radiography data, and 3 were withdrawn from the cohort because of secondary pedicle screw fixation after primary stand-alone surgery due to unbearable low back pain. The demographic baseline characteristics of the patients including age, gender, body mass index (BMI), and bone mineral density (BMD) are described in Table 1 . There was no significant difference in age, sex, or BMI between the two groups, but the BMD in the combined group was significantly lower $(-1.9 \pm 1.3$ vs $-0.9 \pm 1.4, \mathrm{p}=0.005)$.

\section{Surgical management}

All surgeries were performed by senior spine surgeons with more than 20 years of experience and their teams. Generally, after general anesthesia, the patients were placed in the right lateral position, and a standard OLIF procedure was performed, as described in the previous literature [4-6]. In patients who underwent combined OLIF, additional percutaneous PSRF was performed as

Table 1 Baseline characteristics of included patients

\begin{tabular}{llll}
\hline Baseline data & Combined $(\mathbf{n}=\mathbf{2 5})$ & Stand-alone $(\mathbf{n}=\mathbf{4 1})$ & P value \\
\hline Age (year) & $62.16 \pm 8.65$ & $59.46 \pm 8.46$ & 0.217 \\
Gender $(\mathrm{M} / \mathrm{F})$ & $12 / 13$ & $22 / 19$ & 0.800 \\
$\mathrm{BMI}\left(\mathrm{kg} / \mathrm{m}^{2}\right)$ & $24.32 \pm 1.59$ & $24.33 \pm 2.40$ & 0.984 \\
BMD $(T$ value $)$ & $-1.9 \pm 1.3$ & $-0.9 \pm 1.4$ & 0.005 \\
Surgical segment & & \\
$\mathrm{L}_{2 / 3}$ & 0 & 2 & 0.532 \\
$\mathrm{~L}_{3 / 4}$ & 5 & 11 & \\
$\mathrm{~L}_{4 / 5}$ & 20 & 28 & \\
$\mathrm{~L}_{5} / \mathrm{S}_{1}$ & 0 & 0 & \\
\hline
\end{tabular}

$B M I$ body mass index, $B M D$ bone mineral density 
described in previous studies [12, 13]. No direct decompression of the spinal canal was performed.

After the operation, all patients received nonsteroidal drugs, muscle relaxants, and neurotrophic drugs. Lumbar and leg muscle training was conducted under the guidance of physiotherapists. In addition, patients with BMD values between -1.5 and -2.5 received calcium and calcitriol, while patients with BMD values lower than -2.5 received bisphosphonates in addition to the above drugs.

\section{Clinical outcome data collection}

The visual analog scale (VAS) [14] was used to evaluate low-back pain, which was recorded preoperatively, postoperatively, 3 and 6 months postoperatively, and at the last follow-up. Oswestry disability index (ODI) [15] is also measured and recorded at these time points. Surgical-related complications were documented.

\section{Radiography data measurement}

The radiography measurements and interbody fusion evaluations were evaluated by sagittal lumbar computed tomography. We measured the disk height $(\mathrm{DH})$ of each patient's operative segment. The DH was defined as the mean value of the anterior, middle, and posterior heights of the intervertebral space (Fig. 1). The $\Delta \mathrm{DH}$ was defined as the postoperative $\mathrm{DH}$ minus the preoperative $\mathrm{DH}$, which represents the increment in the height of the intervertebral space. The foraminal height (FH) was defined as the mean of bilateral foraminal height, measured perpendicular from the lower edge of cephalic pedicle to the upper edge of caudal pedicle, it indicate the effect of foraminal decompression. The total cage subsidence (tCS) was calculated as the sum of cephalic and caudal subsidence (Fig. 1). Since the tCS is composed of two variable whose length is opposite to that of the cephalic and caudal, and the correlation between CS and clinical outcomes depends mainly on the severity of single CS rather than the sum. Thus, the one with the larger value is considered as the main cage subsidence (mCS). Severe $\mathrm{CS}$ is considered to occur when $\mathrm{mCS}>4 \mathrm{~mm}$ [16]. The evaluation of fusion rate at 6 months postoperatively and at the last follow-up was performed using the Bridwell interbody fusion grading system [17]. If grade I or grade II was reached, the occurrence of interbody fusion was considered. All imaging data were independently and blindly evaluated by two senior radiologists. Controversial measurement results were alleviated by consensus.

\section{Statistical analysis}

SPSS 23.0 software (IBM Co., Armonk, NY, USA) was used to analyze the data. One-sample K-S test was used to check the normality of the measurement data, and the mean \pm SD was used if normality was met. If the data did not obey a normal distribution, we described the variables as $M\left[Q_{1}, Q_{3}\right]$, and the Wilcoxon MannWhitney test was used. Fisher's exact probability method was used to compare the enumeration data between groups. For correlation analysis, related coefficient and multiple linear regression analyses were used. The test standard was set as $\alpha=0.05$.

\section{Results}

\section{Clinical outcomes}

Before surgery, there was no significant difference in the VAS $(6[5.5,7]$ vs $6[5.5,7], \mathrm{p}=0.826)$ or ODI $(62.22$ [53.33, 68.89] vs 57.78 [53.33, 64.44], $\mathrm{p}=0.551$ ) scores between the combined group and stand-alone group. The postoperative VAS and ODI scores decreased significantly in each group and were all maintained well in whole follow-up period. Immediate postoperatively, the
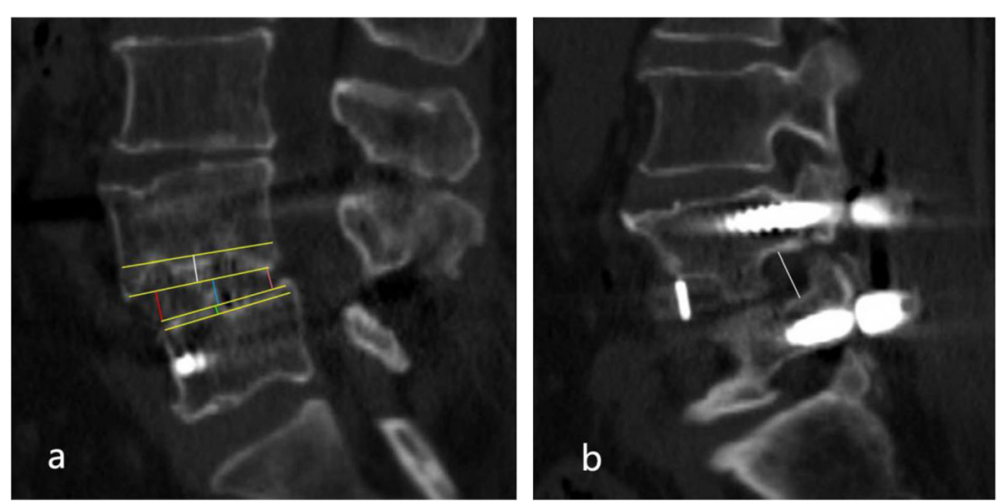

Fig. 1 Measurement of radiological parameters: (a) the boundary of the endplate and the cage is delineated by yellow line. The tCS is defined as the sum of the cephalic CS (white line) and caudal CS (green line), and mCS is the larger one in them. DH is defined as the mean of the anterior DH (red line), middle DH (blue line), and posterior DH (pink line). (b) FH is measured by the perpendicular from the lower edge of the cephalic vertebra pedicle to the upper edge of the caudal vertebra pedicle. FH is the mean value of bilateral FH 
VAS score of the stand-alone group was slightly better than that of the combined group $(3[3,4]$ vs $4[3,5]$, p $=$ 0.012). However, the VAS score in the combined group was better than that in the stand-alone group 3 months after the operation $(3[1.5,3]$ vs $3[2,4], \mathrm{p}=0.038)$. The difference disappeared at 6 months postoperatively and at the last follow-up. There was no significant difference in ODI scores between the groups at any of the time points (Table 2, Fig. 2).

\section{Radiography outcomes}

For all patients, the DH increased by 3.11 [2.12, 4.45] $\mathrm{mm}$ after the operation, but there was no significant difference in the $\Delta \mathrm{DH}$ between the two groups (3.24 [2.03, $4.55]$ vs 3.08 [2.15, 4.33], $\mathrm{p}=0.848)$. The $\mathrm{FH}$ values preoperatively and 3 months postoperatively were comparable between the two groups. There was a significant difference of $\mathrm{FH}$ between the two groups 6 months after the operation $(18.37 \pm 1.98$ vs $17.26 \pm 2.29, \mathrm{p}=0.049)$, and the difference was more significant at the last follow-up $(18.22 \pm 2.00$ vs $16.87 \pm 2.34, \mathrm{p}=0.019)$. The combined group had significantly lower tCS than the stand-alone group at all time points after the operation (all $\mathrm{p} \leq 0.001$ ). The occurrence of severe CS of combined group was lower than that of stand-alone group, but the difference was not significant ( $16 \%$ vs $41.5 \%, \mathrm{p}=0.055$ ). There was no significant difference in the fusion rate between the two groups 6 months after the operation or at the last follow-up ( $92 \%$ vs $90.2 \%, 100 \%$ vs $95.1 \%$, respectively) (Table 3, Fig. 2).

\section{Correlation analysis}

In the combined group, BMD was mildly negatively correlated $(\mathrm{r}=-0.602, \mathrm{p}=0.001)$ with $\mathrm{mCS}$, and BMI was a moderate-intensity positive correlation for $\mathrm{mCS}(\mathrm{r}=$ $0.400, \mathrm{p}=0.047)$, while $\Delta \mathrm{DH}(\mathrm{r}=-0.059, \mathrm{p}=0.781)$ were not significantly correlated with $\mathrm{mCS}$. In contrast, in the stand-alone group, the negative correlation between BMD and $\mathrm{mCS}$ was significantly enhanced $(\mathrm{r}=-0.797, \mathrm{p}$ $<0.001)$, and a correlation between $\mathrm{mCS}$ and BMI $(\mathrm{r}=$ $0.207, \mathrm{p}=0.195)$ or $\Delta \mathrm{DH}(\mathrm{r}=0.271, \mathrm{p}=0.086)$ was not found.

On the other hand, there was only a low to moderate positive correlation between $\mathrm{mCS}$ and VAS $(\mathrm{r}=0.427$, $\mathrm{p}$
$=0.033)$ or ODI $(\mathrm{r}=0.594, \mathrm{p}=0.002)$ scores in the combined group. However, in the stand-alone group, this positive correlation was much stronger with VAS ( $\mathrm{r}$ $=0.685, \mathrm{p}<0.001)$ and DOI $(\mathrm{r}=0.616, \mathrm{p}<0.001)$.

Multiple linear regression showed that only BMD was a risk factor for $\mathrm{mCS}$ in the regression model in the combined group $(\beta=-0.535, \mathrm{p}=0.005)$ and stand-alone group $(\beta=-0.756, \mathrm{p}<0.001)$ (Table 4$)$. Therefore, BMI and $\triangle \mathrm{DH}$ were excluded from the multiple linear regression model, and a simple linear regression model of BMD and mCS was used (Table 5). According to the linear regression model, when severe CS was defined as $\mathrm{mCS}>4 \mathrm{~mm}$, the BMD threshold in the stand-alone group was -1.38 , and the use of PSRF expanded the BMD threshold to -4.77 in the combined group.

\section{Complications}

No cases of major artery injury or spinal nerve injury occurred. One case of segmental artery injury occurred in the stand-alone group, and lumbar myasthenia was relatively more common, with 4 cases occurring in each group. There were 3 cases of sympathetic nerve injury in the combined group and 2 cases in the stand-alone group. There was 1 case of ureteral injury in the standalone group. No cage retropulsion or other complications were observed in either group. Statistical analysis was abandoned due to the small number of complications.

\section{Discussion}

As a kind of anterolateral fusion, the decompression effect of OLIF is indirect, which also leads to the limitation of surgical indications. Generally, the surgical indications of OLIF are lumbar spondylolisthesis below grade II, lumbar disk herniation combined with segmental instability, nerve root canal stenosis caused by loss of disk height, degenerative scoliosis/kyphosis, and degenerative disk disease [18]. Therefore, patients now have a more minimal invasive choice of fusion. To pursue the minimally invasive advantage of OLIF, stand-alone OLIF is widely used, as it has a shorter operation time and less intraoperative bleeding than other operations and does not invade the posterior structure [19].

Table 2 Clinical outcomes of the two groups

\begin{tabular}{|c|c|c|c|c|c|c|c|c|c|}
\hline \multirow[t]{2}{*}{ Groups } & \multicolumn{5}{|c|}{ VAS score } & \multicolumn{4}{|l|}{ ODI (\%) } \\
\hline & Pre-op & Post-op & $3 \mathrm{~m}$ & $6 \mathrm{~m}$ & Last $\mathrm{f}-\mathrm{u}$ & Pre-op & $3 \mathrm{~m}$ & $6 \mathrm{~m}$ & Last $\mathbf{f}-\mathrm{u}$ \\
\hline Combined & $6[5.5,7]$ & $4[3,5]$ & $3[1.5,3]$ & $2[2,3]$ & $2[1.5,2]$ & $62.22[53.33,68.89]$ & $24.44[17.78,28.89]$ & $17.78[15.56,20.00]$ & $15.56[13.33,17.78]$ \\
\hline Stand-alone & $6[5.5,7]$ & $3[3,4]$ & $3[2,4]$ & $2[2,3]$ & $2[2,3]$ & $57.78[53.33,64.44]$ & $26.67[18.89,38.89]$ & $20.00[16.67,22.22]$ & $15.56[13.33,21.11]$ \\
\hline$Z$ value & -0.229 & -2.528 & -2.075 & -1.657 & -1.823 & -0.603 & -1.348 & -1.134 & -0.960 \\
\hline$P$ value & 0.826 & 0.012 & 0.038 & 0.100 & 0.067 & 0.551 & 0.180 & 0.260 & 0.341 \\
\hline
\end{tabular}

VAS visual analog scale, ODI Oswestry disability index 


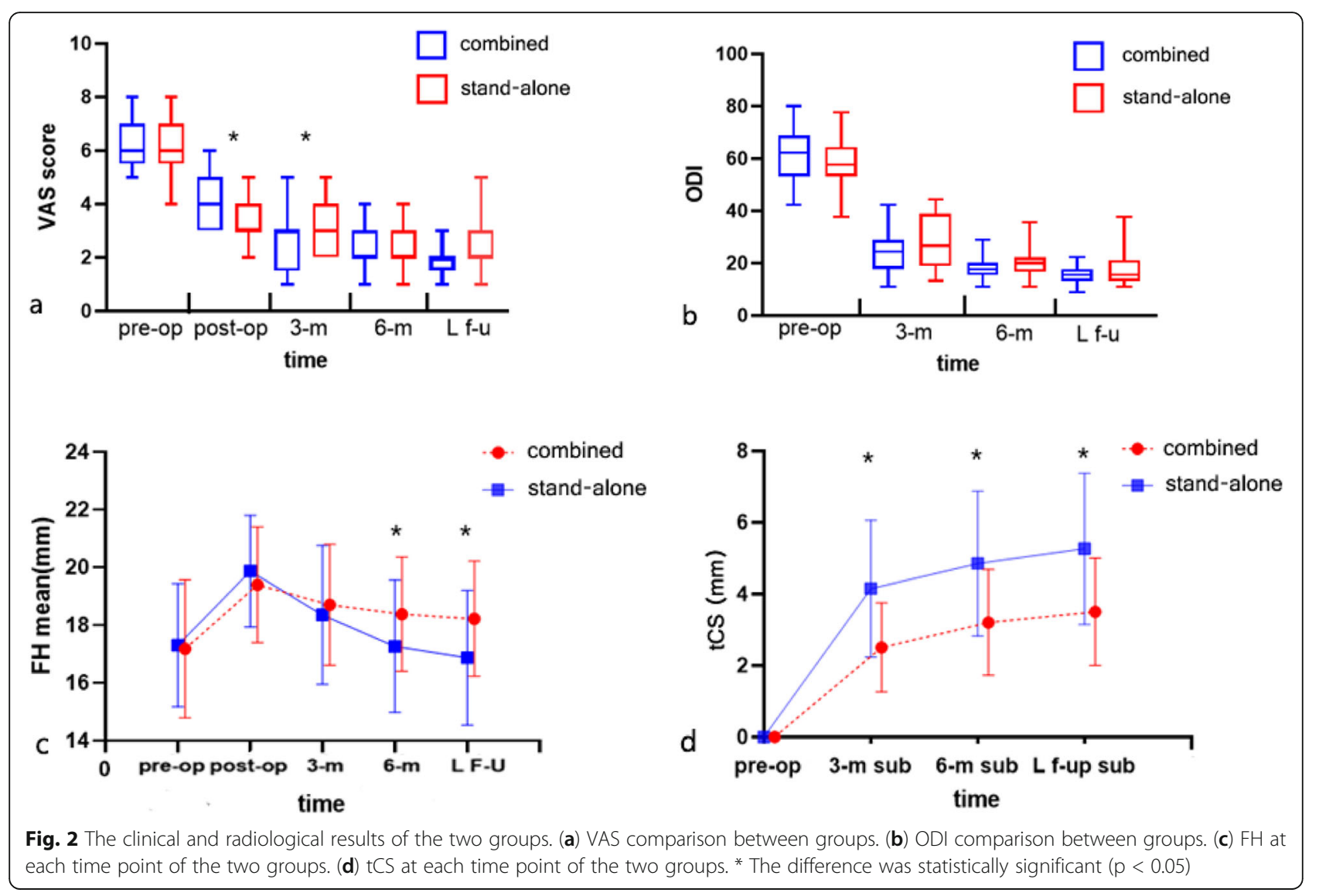

However, stand-alone OLIF method is controversial due to its potential stability defects. Fang G et al. [7] and Guo $\mathrm{Hz}$ et al. [20] found that the stability of stand-alone OLIF was significantly worse than that of combined OLIF through finite element analysis. In contrast, St Clair s et al. proved that the stability, overall stiffness, and failure load of stand-alone OLIF were similar to those of pedicle screw rod fixation systems through biomechanical testing of the human spine in vitro [21]. In clinical studies, the comparison results of stand-alone OLIF and combined OLIF have also been inconsistent.
In some studies, the short-term clinical results of standalone OLIF were better $[9,22]$, but in other studies, the complication rate of stand-alone OLIF was significantly higher than that of combined OLIF [10, 11]. Therefore, the evidence on the risks and benefits of stand-alone/ PSRF method remains mixed.

In addition, the indications of PSRF are ambiguous, some studies have only empirically suggested that patients with a BMD $<-1$ should undergo pedicle screw fixation to prevent subsidence [3]. Other authors believe that additional fixation may be required for patients with

Table 3 Radiological results the two groups

\begin{tabular}{|c|c|c|c|c|c|c|c|c|c|c|c|c|}
\hline \multirow[t]{2}{*}{ Groups } & \multirow{2}{*}{$\begin{array}{l}\Delta \mathrm{DH} \\
(\mathrm{mm})\end{array}$} & \multicolumn{5}{|l|}{$\mathrm{FH}(\mathrm{mm})$} & \multicolumn{3}{|l|}{$\mathrm{tCS}(\mathrm{mm})$} & \multirow{2}{*}{$\begin{array}{l}\text { Severe } \\
\text { CS (> } 4 \\
\mathrm{~mm})\end{array}$} & \multicolumn{2}{|c|}{ Fusion rate } \\
\hline & & Pre-op & Post-op & $3 \mathrm{~m}$ & $6 \mathrm{~m}$ & Last f-u & $3 \mathrm{~m}$ & $6 \mathrm{~m}$ & Last f-u & & $6 \mathrm{~m}$ & Last f-u \\
\hline Combined & $\begin{array}{l}3.24[2.03 \\
4.55]\end{array}$ & $\begin{array}{l}17.18 \pm \\
2.39\end{array}$ & $\begin{array}{l}19.40 \pm \\
2.00\end{array}$ & $\begin{array}{l}18.71 \pm \\
2.10\end{array}$ & $\begin{array}{l}18.37 \pm \\
1.98\end{array}$ & $\begin{array}{l}18.22 \pm \\
2.00\end{array}$ & $\begin{array}{l}2.50 \pm \\
1.24\end{array}$ & $\begin{array}{l}3.20 \pm \\
1.48\end{array}$ & $\begin{array}{l}3.50 \pm \\
1.50\end{array}$ & $\begin{array}{l}4 / 25 \\
(16 \%)\end{array}$ & $\begin{array}{l}23 / 25 \\
(92 \%)\end{array}$ & $\begin{array}{l}25 / 25 \\
(100 \%)\end{array}$ \\
\hline $\begin{array}{l}\text { Stand- } \\
\text { alone }\end{array}$ & $\begin{array}{l}3.08[2.15 \\
4.33]\end{array}$ & $\begin{array}{l}17.31 \pm \\
2.14\end{array}$ & $\begin{array}{l}19.87 \pm \\
1.93\end{array}$ & $\begin{array}{l}18.36 \pm \\
2.41\end{array}$ & $\begin{array}{l}17.26 \pm \\
2.29\end{array}$ & $\begin{array}{l}16.87 \pm \\
2.34\end{array}$ & $\begin{array}{l}4.15 \pm \\
1.91\end{array}$ & $\begin{array}{l}4.85 \pm \\
2.03\end{array}$ & $\begin{array}{l}5.26 \pm \\
2.11\end{array}$ & $\begin{array}{l}17 / 41 \\
(41.5 \%)\end{array}$ & $\begin{array}{l}37 / 41 \\
(90.2 \%)\end{array}$ & $\begin{array}{l}39 / 41 \\
(95.1 \%)\end{array}$ \\
\hline $\begin{array}{l}\text { Statistical } \\
\text { value }\end{array}$ & $Z=-0.192$ & $t=-0.226$ & $t=-0.955$ & $t=0.599$ & $t=2.004$ & $t=2.397$ & $t=-3.837$ & $t=-3.522$ & $t=-3.641$ & 1 & 1 & 1 \\
\hline$P$ value & 0.848 & 0.822 & 0.343 & 0.551 & 0.049 & 0.019 & $<0.001$ & 0.001 & 0.001 & 0.055 & 1.000 & 0.522 \\
\hline
\end{tabular}

$\mathrm{DH}$ diskal height, $\mathrm{FH}$ foraminal height, $t \mathrm{CS}$ total cage subsidence 
Table 4 Multiple linear regression results

\begin{tabular}{llllll}
\hline Groups & Variables & SE & $\boldsymbol{\beta}$ & $\mathbf{9 5 \% C l}$ & P value \\
\hline Combined & Constant & 3.003 & & $(-9.539,2.950)$ & 0.285 \\
& BMD & 0.156 & -0.535 & $(-0.812,-0.164)$ & 0.005 \\
& BMI & 0.125 & 0.268 & $(-0.063,0.457)$ & 0.130 \\
& $\Delta \mathrm{DH}$ & 0.085 & -0.002 & $(-0.177,0.176)$ & 0.992 \\
Stand-alone & Constant & 1.528 & & $(-3.688,2.505)$ & 0.701 \\
& BMD & 0.102 & -0.756 & $(-1.031,-0.618)$ & $<0.001$ \\
& BMI & 0.060 & 0.185 & $(-0.002,0.240)$ & 0.054 \\
& DDH & 0.084 & 0.177 & $(-0.013,0.329)$ & 0.069 \\
\hline
\end{tabular}

Dependent variable mCS, SE standard error, 95\% Cl 95\% confidence interval

a $\mathrm{BMD}<-2.5$ or who with $\mathrm{BMI} \geq 30 \mathrm{~kg} / \mathrm{m}^{2}$ [23]. At present, there is no consensus on when additional implantation is necessary in OLIF surgery.

Biomechanically, stiff support will transfer more gravity load between vertebrae than soft disk tissue before bony fusion achieved. Although the cages used in OLIF are larger than traditional cages, the stress shielding effect is still almost unavoidable in stand-alone fusion [24]. Excessive stress leads to local collapse of the endplate followed by repeated trabecular microfractures under the endplate in daily activities and causes intractable pain [25]. This process gradually stops until the occurrence of curvature coincidence, sub-endplate osteosclerosis, and intervertebral fusion.

In our study, we found a strong negative correlation between BMD and CS, indicating that osteoporosis patients are more prone to the occurrence of CS. The correlation analysis also confirmed a correlation between a larger $\mathrm{mCS}$ and worse VAS and ODI scores. PSRF showed an obvious anti-subsidence effect, and can weaken the positive correlation between $\mathrm{mCS}$ and VAS/ ODI. Previously, Oh kW et al. [26] proved that there was no correlation between CS and clinical results after PLIF surgery. Similarly, we also found that PSRF could prevent the low back pain and disability caused by CS, for the correlation between VAS/ODI and CS was significantly weakened in the combined group. These results demonstrated the effect of interbody stabilization on pain relief.

The ephemeral inferiority in VAS scores immediate postoperatively in the combined group may be caused

Table 5 Simple linear regression results

\begin{tabular}{llllll}
\hline Groups & Variables & SE & $\boldsymbol{\beta}$ & $\mathbf{9 5 \% C l}$ & P value \\
\hline Combined & Constant & 0.342 & & $(0.675,2.090)$ & 0.001 \\
& BMD & 0.152 & -0.602 & $(-0.862,-0.234)$ & 0.001 \\
Stand-alone & Constant & 0.174 & & $(2.451,3.153)$ & $<0.001$ \\
& BMD & 0.106 & -0.797 & $(-1.083,-0.656)$ & $<0.001$ \\
\hline
\end{tabular}

Dependent variable mCS, SE standard error, $95 \%$ Cl 95\% confidence interval by additional posterior surgical trauma. From 6 months to the last follow-up, because interbody fusion was achieved in the majority of patients in both groups, the unstable factors of the intervertebral space were eliminated, induce the difference in pain improvement between the groups disappeared. In terms of functionality improvements, although the ODI scores in the combined group were always slightly better than those in the stand-alone group, there was no significant difference between the two groups.

In this study, although the difference of the incidence of severe CS between the two groups was not significant $(p=0.055)$, we noted that this was due to the significant difference in baseline BMD value between the two groups caused by the non-randomized grouping. If BMD value was similar between the groups, this difference would be further amplified. The correlation analysis showed that osteoporosis was a risk factor for mCS. According to the linear regression models obtained in this study, patients who underwent the stand-alone method were at risk of severe CS when their BMD $<-1.38$. When PSRF was adopted, only patients with a BMD < -4.77 were at equal risk of severe CS.

Interestingly, we found that the BMI did not show a correlation with mCS in any group, which may be because, on the one hand, greater BMI will increase vertebral load as a risk factor, and on the other hand, greater $\mathrm{BMI}$ is a protective factor for osteoporosis in postmenopausal women $[27,28]$. Although the P value of BMI in both groups was greater than 0.05 , we found that the $\mathrm{P}$ value of the stand-alone group was 0.054 , which was very close to 0.05 , suggesting that the correlation between BMI and $\mathrm{mCS}$ was stronger in the stand-alone group than that of the combined group. In addition, it seemed that there was no correlation between the extent of intervertebral space expansion (i.e., $\triangle \mathrm{DH}$ ) and $\mathrm{mCS}$. Based on our data, we believe that the retraction force of the paravertebral ligament is almost negligible compared with the weight load.

The limitations of this study are as follows: (1) The sample size included in this study was still small, which may have caused bias. (2) The BMD T values were obtained before treatment, so the effect of antiosteoporosis treatment was ignored, which may have resulted in an underestimation of subsidence. (3) Due to the nonrandomized grouping of the retrospective studies, significant differences in baseline BMD biased the comparison between the groups, but this did not interfere with the results of the multivariate linear regression analysis within each group.

\section{Conclusions}

In conclusion, we suggest that patients with osteoporosis or osteopenia should avoid the stand-alone OLIF 
method, which may put them at greater risk of developing severe CS. OLIF combined with PSRF can significantly reduce $\mathrm{FH}$ loss and the risk of severe CS than the stand-alone OLIF method, which may benefit clinical outcomes in patients with osteoporosis or osteopenia.

\section{Abbreviations}

PSRF: Pedicle-screw rod fixation; OLIF: Oblique lumbar interbody fusion; CS: Cage subsidence; BMI: Body mass index; BMD: Bone mineral density; VAS: Visual analog scale; ODI: Oswestry disability index; DH: Disk height; $\triangle \mathrm{DH}$ : Disk height increment; FH: Foraminal height; tCS: Total cage subsidence; mCS: Main cage subsidence

\section{Acknowledgements}

The authors thank Professor Xiangqian Fang and his team members from the Department of Orthopaedic of Sir Run Run Shaw Hospital for their cooperation in this study.

\section{Authors' contributions}

KC and KZ: Quantification and data gathering. GJ: Hypothesis and study design. KC, JZ, and SY: Data analysis. KC and KL: Writing and editing. YY: Data maintenance and management. All authors contributed in the final revision of the draft. The authors read and approved the final manuscript.

\section{Funding}

Not applicable.

\section{Availability of data and materials}

None.

\section{Declarations}

\section{Ethics approval and consent to participate}

This study was approved by the clinical ethics committee of The Affiliated Hospital of Medical School of Ningbo University (KY20200906).

\section{Consent for publication}

Not applicable.

\section{Competing interests}

The authors declare that they have no competing interests.

\section{Author details}

'Department of Orthopaedic, The Affiliated Hospital of Medical School of Ningbo University, No. 247, Renmin Road, Jiangbei District, Ningbo, Zhejiang, People's Republic of China. 'Institute of Orthopaedics, Ningbo University, Ningbo, People's Republic of China. ${ }^{3}$ Department of Orthopaedic, Sir Run Run Shaw Hospital, School of Medicine, Zhejiang University, Hangzhou, People's Republic of China. ${ }^{4} T$ The Medical School of Ningbo University, Ningbo, People's Republic of China.

Received: 13 January 2021 Accepted: 17 June 2021

Published online: 03 July 2021

\section{References}

1. Mayer HM. A new microsurgical technique for minimally invasive anterior lumbar interbody fusion. Spine. 1997;22(6):691-9. https://doi.org/10.1097/ 00007632-199703150-00023.

2. Silvestre C, Mac-Thiong JM, Hilmi R, Roussouly P. Complications and morbidities of mini-open anterior retroperitoneal lumbar interbody fusion: oblique lumbar interbody fusion in 179 patients. Asian Spine J. 2012;6(2):89_ 97. https://doi.org/10.4184/asj.2012.6.2.89.

3. Li R, Li X, Zhou H, Jiang W. Development and application of oblique lumbar interbody fusion. Orthop Surg. 2020;12(2):355-65. https://doi.org/10.1111/ os. 12625.

4. Zhu G, Hao Y, Yu L, Cai Y, Yang X. Comparing stand-alone oblique lumbar interbody fusion with posterior lumbar interbody fusion for revision of rostral adjacent segment disease: a STROBE-compliant study. Medicine (Baltimore). 2018;97(40):e12680. https://doi.org/10.1097/MD.0000000000012 680 .
5. Huo $Y$, Yang D, Ma L, Wang H, Ding W, Yang S. Oblique lumbar interbody fusion with stand-alone cages for the treatment of degenerative lumbar spondylolisthesis: a retrospective study with 1-year follow-up. Pain Res Manag. 2020;2020:9016219.

6. Jin C, Xie M, He L, Xu W, Han W, Liang W, et al. Oblique lumbar interbody fusion for adjacent segment disease after posterior lumbar fusion: a casecontrolled study. J Orthop Surg Res. 2019;14(1):216. https://doi.org/10.1186/ s13018-019-1276-9.

7. Fang G, Lin Y, Wu J, Cui W, Zhang S, Guo L, et al. Biomechanical comparison of stand-alone and bilateral pedicle screw fixation for oblique lumbar interbody fusion surgery-a finite element analysis. World Neurosurg. 2020;141:e204-12. https://doi.org/10.1016/j.wneu.2020.05.245.

8. He W, He D, Sun Y, et al. Standalone oblique lateral interbody fusion vs. combined with percutaneous pedicle screw in spondylolisthesis. BMC Musculoskelet Disord. 2020:21(1):184 Published 2020 Mar 23.

9. Abe K, Orita S, Mannoji C, Motegi H, Aramomi M, Ishikawa T, et al. Perioperative complications in 155 patients who underwent oblique lateral interbody fusion surgery: perspectives and indications from a retrospective, multicenter survey.[J]. Spine. 2017;42(1):55-62. https://doi.org/10.1097/BRS. 0000000000001650

10. Liu JP, Wang Q, Feng HL, et al. Clinical analysis of the complications of oblique lateral interbody fusion (OLIF). Chin J Neurosurg Dis Res. 2017;16: $538-41$

11. Zeng ZY, Xu ZW, He DW, Zhao X, Ma WH, Ni WF, et al. Complications and prevention strategies of oblique lateral interbody fusion technique. Orthop Surg. 2018;10(2):98-106. https://doi.org/10.1111/os.12380.

12. Zhao Q, Zhang H, Hao D, Guo H, Wang B, He B. Complications of percutaneous pedicle screw fixation in treating thoracolumbar and lumbar fracture. Medicine (Baltimore). 2018;97(29):e11560. https://doi.org/10.1097/ MD.0000000000011560.

13. Gazzeri R. Percutaneous pedicle screw fixation technique in the thoracic and lumbar spine-tips and tricks. Surg Technol Int. 2016;28:303-10.

14. Aitken RC. Measurement of feelings using visual analogue scales. Proc R Soc Med. 1969;62(10):989-93. https://doi.org/10.1177/003591576906201005.

15. Fairbank JC, Couper J, Davies JB, O'Brien JP. The Oswestry low back pain disability questionnaire. Physiotherapy. 1980;66(8):271-3.

16. Tohmeh AG, Khorsand D, Watson B, Zielinski X. Radiographical and clinical evaluation of extreme lateral interbody fusion: effects of cage size and instrumentation type with a minimum of 1-year follow-up. Spine (Phila Pa 1976). 2014;39(26):E1582-91. https://doi.org/10.1097/BRS.0000000000000645.

17. Bridwell KH, Lenke LG, McEnery KW, et al. Anterior fresh frozen structural allografts in the thoracic and lumbar spine. Do they work if combined with posterior fusion and instrumentation in adult patients with kyphosis or anterior column defects? Spine (Phila Pa 1976). 1995;20(12):1410-8.

18. Xu DS, Walker CT, Godzik J, Turner JD, Smith W, Uribe JS. Minimally invasive anterior, lateral, and oblique lumbar interbody fusion: a literature review. Ann Transl Med. 2018;6(6):104. https://doi.org/10.21037/atm.2018.03.24.

19. Li HM, Zhang RJ, Shen CL. Radiographic and clinical outcomes of oblique lateral interbody fusion versus minimally invasive transforaminal lumbar interbody fusion for degenerative lumbar disease. World Neurosurg. 2019; 122:e627-38. https://doi.org/10.1016/j.wneu.2018.10.115.

20. Guo HZ, Tang YC, Guo DQ, Luo PJ, Li YX, Mo GY, et al. Stability evaluation of oblique lumbar interbody fusion constructs with various fixation options: a finite element analysis based on three-dimensional scanning models. World Neurosurg. 2020;138:e530-8. https://doi.org/10.1016/j.wneu.2020.02.1 80 .

21. St Clair S, Tan JS, Lieberman I. Oblique lumbar interbody fixation: a biomechanical study in human spines. J Spinal Disord Tech. 2012;25(4):1839. https://doi.org/10.1097/BSD.0b013e318211fc6b.

22. He W, He D, Sun Y, et al. Quantitative analysis of paraspinal muscle atrophy after oblique lateral interbody fusion alone vs. combined with percutaneous pedicle screw fixation in patients with spondylolisthesis. BMC Musculoskelet Disord. 2020;21(1):30 Published 2020 Jan 14

23. Wang YP, An JL, Sun YP, et al. Comparison of outcomes between minimally invasive transforaminal lumbar interbody fusion and traditional posterior lumbar intervertebral fusion in obese patients with lumbar disk prolapse. Ther Clin Risk Manag. 2017;13:87-94 Published 2017 Jan 19.

24. Calvo-Echenique A, Cego?ino J, Chueca R, et al. Stand-alone lumbar cage subsidence: a biomechanical sensitivity study of cage design and placement. Comput Methods Programs Biomed. 2018;162:211-219, doi: https://doi.org/10.1016/j.cmpb.2018.05.022. 
25. Palepu V, Helgeson M, Molyneaux-Francis M, et al. The effects of bone microstructure on subsidence risk for ALIF, LLIF, PLIF, AND TLIF spine cages [published online ahead of print, 2018 Dec 5]. J Biomech Eng. 2018;10.1115/ 1.4042181.

26. Oh KW, Lee JH, Lee JH, Lee DY, Shim HJ. The correlation between cage subsidence, bone mineral density, and clinical results in posterior lumbar interbody fusion. Clin Spine Surg. 2017;30(6):E683-9. https://doi.org/10.1097/ BSD.0000000000000315.

27. Tian L, Yang R, Wei L, Liu J, Yang Y, Shao F, et al. Prevalence of osteoporosis and related lifestyle and metabolic factors of postmenopausal women and elderly men: a cross-sectional study in Gansu province, Northwestern of China. Medicine (Baltimore). 2017;96(43):e8294. https://doi.org/10.1097/MD. 0000000000008294.

28. Yan G, Huang Y, Cao H, Wu J, Jiang N, Cao X. Association of breastfeeding and postmenopausal osteoporosis in Chinese women: a community-based retrospective study. BMC Womens Health. 2019;19(1):110. https://doi.org/1 0.1186/s12905-019-0808-0.

\section{Publisher's Note}

Springer Nature remains neutral with regard to jurisdictional claims in published maps and institutional affiliations.

Ready to submit your research? Choose BMC and benefit from:

- fast, convenient online submission

- thorough peer review by experienced researchers in your field

- rapid publication on acceptance

- support for research data, including large and complex data types

- gold Open Access which fosters wider collaboration and increased citations

- maximum visibility for your research: over $100 \mathrm{M}$ website views per year

At $\mathrm{BMC}$, research is always in progress.

Learn more biomedcentral.com/submissions 